\title{
La lengua escrita en el Ciclo Medio. I
}

\author{
Nuria Vilà
}

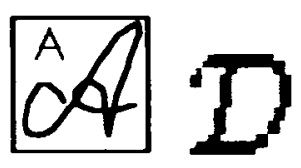

La lenguia escrita ba sido una de las grandes olvidadas de las diversas propuestas curriculares de la educación española. Limitada en la mayoría de los casos por el estrecho corsé de las «redacciones», los ejercicios o exámenes escritos, no es de extrañar que la lengua escrita sea considerada por el alumno como una tarea tediosa y que no tiene nada que ver con su vida de todos los días fuera de la escuela. En este artículo, que por su extensión será publicado en dos partes, se levanta una voz contra ese estado de cosas y tras una caracterización de los diversos tipos de producciones escritas con que el alumno se enfrenta sin saberlo todos los días, se proponen vías de utilización didáctica no sólo en clase de lengua, sino en las restantes áreas del curriculum.

\section{LA EXPRESION ESCRITA DENTRO DEL AMBITO ESCOLAR}

La escritura se define como la utilización gräfica de la lengua que se aplica en ocasiones y contextos determinados, con características y dinámica propias $y$, por lo tanto, distintas de la lengua oral. En consecuencia, las aplicaciones de una y otra no resultan ser exactamente las mismas; cada una genera su propio código particular y su propia forma de expresión. Es, pues, erróneo considerar al código escrito tan sólo como un sistema de signos destinados a transcribir los elementos de la lengua oral, porque él, en sí mismo, ya constituye un medio de comunicación independiente, lo que repercute decisivamente en la enseñanza de la lengua escrita. (Cassany, 1987)

La comunicación humana tiene su exponente máximo en la lengua oral, pero a la hora de su realización los sistemas actuales, tanto la informática como los medios audiovisuales, han agilizado cuando no substituido, la utilización de otros sistemas más convencionales. Con todo, la lengua escrita continúa siendo un valor cultural que regula, de forma importante, las relaciones humanas. Así, en nuestra sociedad constituye una marca de prestigio social y el hecho de aprender a leer y a escribir se considera imprescindible para todo individuo que desee integrarse plenamente en ella.

En la escuela, la lengua escrita va unida a la mayoría de los procesos escolares. La forma en que se trabaja es un reflejo del funcionamiento general de la 
clase de lengua y evidencia el tratamiento global dado a esta materia que, con frecuencia, aparece considerada únicamente como una disciplina más «que se enseña» - a la manera de las matemáticas o de la música-, cuando la realidad nos demuestra que, a pesar de la práctica constante durante ocho años, el grado de dominio que el alumno posee al finalizar la EGB resulta claramente deficitario y exigiría un trabajo más específico de aprendizaje en algunos niveles. Como dato significativo, en el Ciclo Medio se produce un estancamiento en la producción y sobre todo, en la calidad de los textos.

Esta concepción restrictiva de la lengua únicamente como materia se contradice con la filosofía de las nuevas corrientes lingüisticas que la contemplan desde una perspectiva más amplia, la cual incluye tanto los aspectos de reflexión, como los de socialización, o los meramente comunicativos.

Por su parte, la escuela tiende más a fomentar la reflexión o metalingüística - con el correspondiente poder coercitivo-, que a potenciar la expansión lingüística de los alumnos. Cazden (1982) define así el fenómeno:

«En el aprendizaje escolar, los maestros proporcionan directrices y los alumnos las ejecutan sin verbalizar; los maestros hacen preguntas, y los alumnos responden, frecuentemente, con una sola frase o palabra. Lo que resulta más significativo es el carácter no reversible de estos papeles, y menos dentro del contexto de las interacciones entre profesor y alumno. Estos últimos nunca dan directrices a sus maestros; las preguntas que realizan son escasas, excepto aquéllas permitida por el profesor. El único contexto en el que los niños pueden invertir los papeles interactivos con el mismo contenido intelectual, es decir, dando directrices o ejecutándolas, haciendo preguntas o contestándolas, se sitúa en la relación con sus compañeros o con sus padres.»

Su propuesta para reformar la enseñanza de la lengua escrita pasa por un cambio general del sistema de instrucción, de las relaciones que se establecen entre los componentes del aula y de la dinámica global de la clase:

«Se consigue una mejoría importante en la motivación del aprendizaje de la lec. tura y de la escritura, si se modifica la manera en que la escuela afecta los contextos mentales internos de los alumnos en relación a los textos y al conocimiento del mundo, y si se cambian los contextos sociales externos de interacción con el maestro y con los demás alumnos.»

Para llegar a una formulación del papel de la lengua escrita en el ámbito escolar, será preciso analizar antes cómo se realiza la enseñanza de esta disciplina, qué papel juega el maestro y cuál es la posición del alumno delante de esta materia.

En el mundo real de la escuela observamos que, con frecuencia, este tipo de práctica se reduce a formular una serie de ejercicios, más o menos cerrados, pensados para adquirir determinados mecanismos sobre las características de la lengua, más que para trabajar el hecho comunicativo. Con este espíritu, el alumno se enfrenta a la lengua escrita como si fuese una obligación más dentro de las tareas escolares, porque en ningún momento sus producciones escritas tendrán otro destinatario que el propio maestro, ni otra finalidad que acumularse en una carpeta junto con los demás trabajos de Matemáticas o Sociales.

En otras ocasiones, y sobre todo cuando se proponen trabajos más creativos, como los realizados bajo la forma de textos, éstos son aprovechados a posteriori por el maestro para corregir la ortografía, el léxico, o la puntuación. De este modo se acaba trabajando la normativa y la reflexión lingüística en vez de 
actuar sobre la comunicación que por sí sola debería ser el objetivo predominante en este tipo de situaciones.

En lo tocante a las técnicas propuestas, se trabaja casi exclusivamente la narración y, con menos frecuencia, la descripción. ${ }^{1}$.

Ultimamente proliferan también algunos trabajos, que por lo común se inspiran en los propuestos por Gianni Rodari, destinados a fomentar la creatividad y la capacidad de imaginación. Sin embargo, podemos constatar que la función dominante, y a veces la única, sigue siendo la función poética, es decir, aquélla que considera el mensaje como una realización estética. En ocasiones, y sobre todo en los niveles más altos, es posible trabajar con otros tipos de funciones -realización de resúmenes, análisis de la publicidad o de los medios de comunicación...-, pero resulta difícil encontrar una programación de lengua escrita que complete todas las posibilidades y que determine en qué momento se debe trabajar cada tipo de texto.

Nos encontramos, pues, frente a unos trabajos aislados y sin continuidad entre un nivel y otro; frente a unos trabajos que, con frecuencia, exigen a los alumno unos resultados concretos sin que previamente se les hayan proporcionado los instrumentos necesarios para alcanzar los objetivos propuestos; en definitiva, se evalúan unos conocimientos sin que se hayan cumplido las etapas previas inherentes a todo proceso de enseñanza-aprendizaje.

El tipo de ejercicios más habitual en las escuelas se basa fundamentalmente en dos modelos:

* El texto libre: El alumno escribe libremente sin indicación de tema, aun-

que dentro de un horario determinado, lo que repercute en la pretendida «libertad» del texto.

* La redacción: Se escribe a partir de un título o de una propuesta determinados por el maestro.

Tal como están planteados, ninguno de los dos modelos asegura que el alumno aprenderá a escribir porque no contemplan ni la progresión ni tampoco la consecución de unos objetivos claros. Evidentemente, el niño progresa, pero lo hace aisladamente, sin que se establezca el necesario feeb-back entre él mismo y las aportaciones del mundo adulto, que debe descubrir a partir de la comunicación con el maestro y/o la información que le ofrece su entorno, tanto el escolar como el social.

Por otra parte, los programas de expresión escrita, cuya imprecisión ya señalábamos antes, son básicamente intuitivos; sus contenidos y sus actividades carecen de una base teórica -lingüística o literaria-, que, de algún modo, los justifique.

En consecuencia, la práctica de la lengua escrita se reduce por lo tanto a trabajos puntuales, frecuentemente sometidos a la libertad plena del alumno, desconectados entre sí, apenas dotados de unos objetivos confusos y de unas propuestas poco estimulantes y, en fin, carentes de un método sistemático que contemple qué y cómo se ha de introducir el aprendizaje de la lengua escrita en cada curso, tal y como sucede en otras parcelas de la enseñanza.

\section{LA DIVERSIDAD DE USOS DE LA LENGUA ESCRITA}

No resulta tarea fácil desgranar unos objetivos globales precisos para cada curso que determinen el nivel óptimo del alumno en el dominio de la lengua es- 
crita. Tal como sucede con la expresión oral, las diferencias entre los componentes de un grupo-clase suelen ser bastantes significativas debido a la presencia de múltiples variables, entre las cuales destacaríamos las siguientes:

* el nivel intelectual del alumno

* la madurez psicológica

* la facilidad y el gusto por la lengua

* las lecturas previas

* la procedencia socio-cultural

Sin embargo, lo que resulta ser indiscutible es el hecho de que los alumnos, al margen incluso del ámbito escolar, escriben, y a menudo tan sólo por el gusto de hacerlo.

Cazden (1982) hace referencia a una investigación de Fiering (1981) donde se estudió la escritura espontánea del niño, denominada «no-oficial» por la autora, puesto que se trata de producciones no solicitadas por el maestro y que, en general, no son valoradas por los enseñantes. La investigación señala la gran variedad de tipologías textuales que los niños producen en sus intercambios espontáneos:

«...En 184 muestras de escritura no-oficial, espontánea y no solicitada, se localizaron 45 etiquetas e indicaciones para objetos o dibujos; 23 imitaciones de documentos «oficiales» como los billetes de viaje; 15 notas y cartas; 12 canciones y poemas; 13 listas; 8 juegos de palabras; una cantidad no determinada de copias de libros, que Fiering, evidenciando una notable sensibilidad a la par que agudeza, describe como una «realización fantasma» de la escritura, una forma de participar en la lengua escrita (p. 124) a pesar de carecer de las habilidades técnicas precisas; y muchas cosas más. Para todos aquellos niños, la lecto-escritura se había convertido en una fuerza poderosa dentro de su vida.»

\section{Y añade:}

«Todas estas formas de lecto-escritura no oficial son importantes por sí mismas como medios a través de los cuales los niños asumen el lenguaje escrito. Además, son expresiones de una motivación espontánea hacia la lecto-escritura que puede ser convenientemente dirigida hacia finalidades más oficiales.»

Es decir, al alumno no se le debe enseñar todo y de golpe sobre la escritura porque ya posee unos conocimientos implícitos. Blanche-Benveniste (1982) afirma que las personas, o en este caso los escolares, tienen unas ideas preconcebidas de cómo ha de ser el lenguaje escrito, y estas ideas son previas a la pautas que el enseñante dé sobre cómo se debe realizar la escritura.

A pesar de eso, el alumnado encuentra en el discurso escrito muchas más dificultades que las que perciben en el discurso oral, porque, tal como explica Vygotski (1972), está sujeto a unas leyes reguladoras que no se dan en el discurso oral, mucho más inmediato y con una utilidad mayor para el mundo infantil:

«El discurso oral siempre es comprensible: se trata de una comunicación viva con los demás, una reacción completamente natural, un grito de respuesta a todo lo que se agita en su entorno y le implica. Al pasar al discurso escrito, que resulta mucho más abstracto y convencional, a menudo no entiende por qué debe utilizarse. Carece de la exigencia interior de la escritura.»

Y a continuación comenta en términos parecidos, el papel de la escuela tradicional en la enseñanza de la lengua escrita:

«...Todo lo señalado se hace más evidente cuando el niño escribe sobre temas propuestos por la escuela. En la enseñanza tradicional, el desarrollo de la creatividad li- 
teraria se orientaba sobre todo de manera que los alumnos debían desarrollar el tema señalado por el profesor, procurando acercarse en lo posible a una forma literaria parecida al estilo de los libros de lectura obligatoria. Eran temas extraños para su comprensión, y no estimulaban ni su imaginación, ni sus sentimientos. A los niños no se les daban ejemplos de cómo se debía escribir. Resultaba inhabitual que el trabajo exigido fuera unido a una finalidad comprensible, cercana, accesible para ellos...»

Desde hace ya tiempo, la presencia de la lengua escrita es un hecho cotidiano: los carteles, los anuncios, los periódicos, las etiquetas... todos estos elementos forman parte del entorno social del alumno, que diferencia espontáneamente unos textos de otros. Un niño del Ciclo Inicial sabe distinguir, sin grandes dificultades, una carta de una poesía. Sin embargo, es preciso que sean conscientes del proceso y que de este modo, puedan interiorizar una serie de técnicas y recursos que les ayuden a producir textos coherentes y bien construidos. Por este motivo, creemos necesario establecer un trabajo sistemático, que se iniciaría tan pronto como el alumno entrase en contacto con la lengua escrita, es decir, desde sus primeros años de escolarización, y que se prolongaría hasta el último curso de la enseñanza primaria.

\section{APRENDER A ESCRIBIR}

Entendemos el aprendizaje de la escritura como el desarrollo de unas estrategias encaminadas a comprender y utilizar la diversidad de funciones de la lengua escrita. Este aprendizaje está constituido por dos componentes paralelos y complementarios que son:

\section{La motivación: el alumno se expresa porque siente necesidad de bacerlo.}

Es necesario desvelar el interés por la lengua escrita, un interés que se basa en la necesidad -la lengua escrita resulta hoy en día imprescindible en nuestra sociedad-, y en el gusto, -escribir puede ser un placer al alcance de cualquiera-. El alumno debe sentir la necesidad de escribir y es función del maestro fomentar y estimular esta necesidad.

\section{Los recursos: el niño se expresa porque posee la capacidad de bacerlo.}

Hay que distinguir entre el interés y las posibilidades. Un alumno puede llegar a sentirse muy motivado para escribir, pero si esto no va acompañado del desarrollo paralelo de sus conocimientos, muy pronto se encontrará falto de recursos ténicos.

A la hora de planificar los puntos concretos del proceso de aprendizaje de la lengua escrita, el profesor suele enfrentarse a dos dificultades principales: la primera, establecer los objetivos que deben alcanzarse en cada etapa; la segunda, escoger las actividades que han de realizarse con el fin de que el alumno adquiera las habilidades necesarias para progresar, porque, en resumidas cuentas, escribir es una habilidad que se aprende como cualquier otra.

La práctica de la lengua escrita ha sido, a menudo, concebida tan sólo como un recurso de verificación de la capacidad «literaria» del alumno, capacidad que a su vez era muy poco estimulada desde la propia escuela, autolimitada, en ocasiones, a la producción de enunciados o títulos de redacciones que los alumnos debían desarrollar.

Mientras la lengua escrita no abandone su función marginal dentro del curriculum escolar, y en tanto no se introduzcan unos procesos específicos pensados para su asimilación sistemática en cada curso, ciclo, y en el conjunto de la 
EGB, los alumnos continuarán manifestando, al acabar su escolarización, las deficiencias que tanto preocupan a los profesores del Ciclo Superior y de la enseñanza secundaria y que éstos se sieten incapaces de compensar.

Se trataría, pues, de fomentar, por un lado la necesaria espontaneidad y por otro la utilización de los instrumentos precisos para que el alumno aprenda a expresarse, al mismo tiempo que asimila la multiplicidad de usos y de aplicaciones que ofrece la lengua escrita. En definitiva, aprende las diversas técnicas que le permitirán expresar el mensaje que desea transmitir, con la forma lingüística más adecuada. Motivación y recursos son, por lo tanto, partes esenciales de un todo global.

La multiplicidad de usos que citábamos anteriormente se refiere a las distintas aplicaciones y modelos que a menudo quedan relegadas en el trabajo escolar. Tradicionalmente predomina el tipo de trabajo narrativo, primero porque es el más utilizado por el alumno en sus textos libres, y después, porque el hecho de trabajar casi siempre a partir de textos literarios - concretamente, cuentos o narraciones-, incrementa su uso lingüístico. Es más, cuando trabaja con otros modelos (notas, apuntes, resúmenes,...) resulta frecuente que deba hacerlo de una forma espontánea, sin haber recibido antes una explicación de las características técnicas de cada uno.

\section{LA TIPOLOGIA TEXTUAL: UN INSTRUMENTO PRACTICO DE APLICACION ESCOLAR}

La lengua cumple un papel que va mucho más allá de la mera función estética porque es básicamente comunicación y como tal presenta una gran complejidad. Diversos lingüistas han acotado los usos lingüísticos y han fijado la diferentes funciones de la lengua en el proceso de comunicación. Para la elaboración de esta propuesta nos hemos basado en las funciones establecidas por Jakobson, en lo referente al hecho comunicativo, y en la propuesta de Adam, por lo que respecta a la tipología textual.

Las ciencias del lenguaje van introduciéndose lentamente en el mundo escolar. Las programaciones, los libros de texto, los objetivos específicos, el metalenguaje que se utiliza: todos los aspectos formales, en conjunto, están basados en las nuevas corrientes lingüísticas; pero en la práctica resulta difícil traspasar la barrera de las formulaciones teóricas, y aún más comprometido el preparar, de una forma rigurosa, a los enseñantes en activo, de tal modo que comprendan y asuman los postulados citados. Paradóiicamente, los maestros continúan siendo los transmisores de unos conocimientos y los ejecutores de unas programaciones de las que desconocen a menudo sus fundamentos teóricos.

Uno de los objetivos de la lingüística moderna y de su aplicación escolar se basa en el intento de superar las opciones meramente sintácticas para introducir un enfoque más funcional de la lengua que vendría a substituir o a complementar el estudio de la unidad frase. Las nociones de texto o dicurso, como formas de actividad humana, constituirían la posible alternativa. (Bronckart, 1985).

Según esta concepción, los actos del habla formarían la base del conjunto del funcionamiento verbal. De este modo, la clase de lengua, o mejor dicho el proceso de enseñanza-aprendizaje de la lengua en la escuela, comprendería un aspecto más formal, que se ocuparía del estudio de la lengua potencial, como un elemento abstracto y como un objeto de reflexión; y una vertiente pragmática que estudiaría el uso. 
El equilibrio y la progresión entre ambas partes deben fundamentar el curriculum lingüístico del alumno de EGB, que, según las circunstancias y el momento percibirá más o menos potenciado uno de los dos aspectos, pero siempre sin perder de vista que ambos constituyen el anverso y reverso de una misma moneda y en consecuencia se influencían e interrelacionan mutuamente.

La pragmática de la lengua debe ser estudiada en el marco general del hecho comunicativo, el cual incluye situaciones lingüísticas y sociales diversas, porque la actividad comunicativa es esencialmente social e interactiva. Jakobson (1975) ejemplifica de este modo lo antes citado:

$\begin{array}{cc}\text { Contexto } & \\ \text { Mensaje } & \text { Receptor } \\ \text { Contacto-Canal } & \text { Código }\end{array}$

Y a partir de estos seis aspectos básicos del lenguaje, determina las funciones comunicativas siguientes:

* Función conativa. Tiene como finalidad convencer, seducir, incitar o provocar una respuesta del receptor. Está orientada hacia el destinatario y es la función primordial de la publicidad, del discurso político y de la propaganda de todo tipo. Su expresión gramatical más pura la constituyen el vocativo y el imperativo.

* Función expresiva. También se denomina emotiva. Su objetivo es expresar emociones, opiniones, sentimientos... Básicamente centrada en la actitud del destinador o emisor, tiende a producir un reflejo emocional. Es la función que predomina en las cartas personales, en la críticas literarias, teatrales, y en algunos aspectos de la prensa... El nivel puramente emocional está representado por las interjecciones y es una función que habitualmente acompaña nuestras elocuciones tanto en el aspecto fónico, como en el léxico o en el gramatical.

* Función fática. Es la función del contacto. Atrayendo la atención del interlocutor mantiene la comunicación abierta, aunque también la puede dar por acabada. Es la que usualmente utiliza el maestro en el aula: "¿Me seguís?», «¿Lo habéis entendido?». Se emplea en los medios de comunicación, en la publicidad, en determinados textos didácticos... Da lugar a numerosas formas ritualizadas y está orientada hacia el contacto.

* Función metalingüística. Sirve para explicar y hacer comprender los códigos, tal como se hace en los diccionarios, en las gramáticas, en las reglas de un juego o en las recetas de cocina... Tiene también una aplicación habitual en la escuela. Se centra en el código y cualquier proceso de aprendizaje de una lengua aplica operaciones metalingüísticas.

* Función poética. Es la función primordial del arte verbal. Orientada hacia el mensaje considera a éste como una elaboración estética. Comprende la literatura en general, las canciones, y algún tipo de publicidad... Resulta ser una de las funciones más trabajadas escolarmente, con una presencia considerable en todo tipo de mensaje.

* Función referencial. Predomina en las informaciones objetivas y realistas, como las que encontramos en los libros científicos, en la prensa, en los rótulos y carteles, en el resumen... Está orientada hacia el contexto que rodea la actividad comunicativa.

En las situaciones de comunicación no se suelen dar las funciones puras, 
pero en todo mensaje existe una que predomina. Hemos partido de esta clasificación como marco de referencia para que el maestro conozca cuál es la funcionalidad que trabaja en cada propuesta de expresión escrita, y sobre todo, para que sea consciente de la diversidad que significa el hecho comunicativo.

Por su parte, la tipología textual de Adam nos suministra otro marco teórico más relacionado con el texto en concreto.

Adam, en su artículo «Quel types de textes» (Adam, 1985) recoge la clasificación textual de Werlich (E. Werlich, Typologie der Texte, Heidelberg, Quelle \& Meyer, 1975), el cual, basándose en los procesos cognitivos característicos o dominantes, distingue cinco tipos textuales diferentes:

1. Descriptivo: organización espacial

2. Narrativo: desarrollo temporal

3. Expositivo (o explicativo): análisis y síntesis de representaciones conceptuales

4. Argumentativo: toma de posición

5. Instructivo:incitación a la acción

Adam amplía esta clasificación con tres tipos más:

6. Predictivo: predicción de lo que ha de suceder

7. Conversacional: conversación

8. Retórico: creación poética y juego lingüístico

La aplicación de este modelo de clasificación textual al programa escolar de lengua escrita, y concretamente en este caso al programa del Ciclo Medio, exige una explicación de cada uno de los tipos, a la vez que implica una especificación de los contenidos que corresponden a los distintos enunciados:

1. Texto descriptivo. Comprende los textos que definen o describen un concepto, una palabra, un paisaje, y que se organizan según el siguiente esquema: palabra inicial-denominación $>$ definición $>$ expansión

Exige una organización textual que asegure la organización sintáctica mediante bloques cohesionados y organizados por los conectores, así como las relaciones semánticas, como por ejemplo las de hiponimia.

En este apartado se incluyen las definiciones de diccionario y de enciclopedia y en general, todo tipo de descripción: de un producto (publicidad), de un pueblo, de un objeto...

2. Texto narrativo. Abarca los textos que relatan hechos. Se caracteriza por disponer de un desarrollo causal y temporal conjunto. Espacio y tiempo configuran un entramado básico, adopta una forma determinada y se estructura en partes fácilmente identificables. Es el tipo de texto más conocido y el que más se trabaja en el mundo escolar.

Algunos ejemplos de texto narrativo son: el reportaje, la novela, ciertas manifestaciones publicitarias, el cine, las historietas ilustradas, el relato oral, etc.

3. Texto explicativo. Incluye el dicurso científico y el discurso didáctico, o sea, todo lo que presupone una explicación destinada a hacer comprender algo. Se apoya en el uso habitual de conectores de tipo: porque, ya que, de manera que...

Es un discurso frecuente en el ámbito escolar, sobre todo en lo referente a las explicaciones del profesor, pero también en el uso que hacen los alum- 
nos en sus exposiciones orales o en los trabajos escritos que giran alrededor de un tema.

4. Texto argumentativo. Comprende aquellos textos que pretenden demostrar y argumentar una tesis. La estructura de este modelo incluye una premisa, la explicitación de los argumentos y las conclusiones. Sus conectores habituales son del tipo: así pues, pero, etc.

En la lengua oral resulta el modelo predominante en las asambleas de clase que se producen en el entorno escolar, pero por el contrario no es un modelo habitual en el texto escrito, sobre todo en los ciclos Inicial y Medio.

5. Texto instructivo. Caracteriza a aquellos textos que incitan o inducen a realizar alguna acción. Están ordenados cronológicamente porque tal circunstancia es básica para su realización. Aquí se incluyen las recetas de cocina, las instrucciones de montaje y uso de los apartados, las reglas de un juego, y las consignas en general.

Tradicionalmente no ha tenido una presencia usual en la escuela pero resulta interesante no descuidarlo porque exige una estructuración y una organización que nos parecen importantes aplicadas a la planificación de un proyecto literario.

6. Texto predictivo. Incluye aquellos textos donde se anuncia o se predice algún hecho, como sucede con el boletín meteorológico o con los horóscopos. No se trabaja asiduamente, por lo menos en los primeros niveles, pero a veces aparecen a partir de algunas propuestas de los libros de texto de lengua, de sociales o de naturales.

7. Texto conversacional. Comprende los textos que presuponen diálogo, como la entrevista y la conversación, en general. Tienen unas características y una estructura muy determinadas y aparece con frecuencia en muchos trabajos escolares. En este apartado suelen ser habituales las preguntas, las excusas, los agradecimientos, las promesas...

8. Texto retórico. Abarca los textos considerados como creación literaria, sobre todo, aquellos que son más puros, como la poesía, la prosa poética, los refranes, las canciones... Todos los aspectos formales (fónicos, sintácticos, gráficos...) poseen una especial importancia en este modelo textual y aparecen estrechamente ligados al contenido.

Al establecer esta doble clasificación (Jakobson/Adam) basada en la complementariedad de ambas, nuestra intención básica es poder explicar al maestro qué aspectos lingüísticos, cognitivos y literarios se pueden trabajar a partir de cada una de las propuestas que constituyen el programa. A esto hay que añadir que las tipologías textuales, al igual que sucede con las funciones lingüísticas, no aparecen normalmente en estado puro. A menudo, la totalidad de un texto está formada por fragmentos diversos en los que predomina una u otra tipología, según que el contenido y el desarrollo del discurso así lo exijan.

La lengua escrita que debe trabajarse en la escuela gira básicamente alrededor de dos ejes: la literatura y la funcionalidad.

Ya hemos señalado reiteradamente que los textos más habituales en el ámbito escolar son los retóricos y los narrativos centrados en la función poética; en definitiva, aquellos que aparecen íntimamente ligados a la literatura. Pero ésta es sólo una de las funciones de la lengua y es preciso que la escuela cubra también las demás que, si bien no son tan frecuentes, deben ser trabajadas de forma más asidua y sistemática. 
Cuando hablamos de funcionalidad de la lengua escrita nos referimos, por consiguiente, al uso habitual que aparece en los medios de comunicación, en la publicidad, en los diccionarios, en los libros de texto, etc. También el alumno debe penetrar en las características de otros tipos de texto, mediante un trabajo que permita su conocimiento y dominio. Ello nos lleva a considerar el tema de en qué momento hay que trabajar cada tipología textual.

\section{PROPUESTA DE APLICACION}

Con el objeto de asegurar una actividad de lengua escrita que dé cabida a este amplio abanico de posibilidades, deberemos establecer un curriculum lingüístico que contemple tres aspectos fundamentales:

1. La realización de actividades lingüísticas sistemáticas que estén presentes en el ámbito global de las diferentes materias.

2. La concreción en una programación vertical que asegure la continuidad de estas actividades a lo largo de toda la escolarización.

3. La introducción de las diversas tipologías textuales a partir de una metodología que asegure su adquisición.

Las actividades lingüísticas, que pueden ser motivadas por el entorno escolar o por el social, o bien simuladas, no se han de ceñir únicamente a la clase de lengua, si entendemos el hecho comunicativo en toda su extensión. Por este motivo consideramos que estas actividades se deben articular a partir de tres ejes.

1. Las relacionadas únicamente con la clase de lengua.

2. Las que dependen de otras áreas.

3. Las surgidas a partir de otras actividades escolares (carnaval, fiestas navideñas...)

Cualquier texto es por naturaleza interdisciplinario, y esto se debe tanto a que puede ser considerado desde diversos puntos de vista: estético, formal, socológico, histórico, psicológico, etc...como a que la utilización de la lengua escrita en la escuela es el soporte estructural de todas las materias y de buena parte de las actividades escolares.

Los alumnos, durante su vida escolar, deberán realizar resúmenes cuando trabajan las Ciencias, las Sociales, la Música, etc.; utilizarán las definiciones cuando elaboren el diccionario de clase, en el caso de los más pequeños, o las experiencias de Geometría, Matemáticas o Ciencias, en el caso de los mayores; dominarán la técnica descriptiva y las diferencias entre una descripción literaria y una descripción científica; y por último, evidentemente narrarán sucesos reales o imaginarios, escribirán cartas, tomarán notas, prepararán, quizás, algún artículo para la revista escolar o escribirán alguna poesía para una celebración señalada.

Resulta por lo tanto imprescindible establecer una programación de lengua escrita que contemple todas sus aplicaciones en relación a las diversas materias para que el alumno comprenda sus posibilidades reales de utilización y la necesidad de su dominio. A partir de este planteamiento, la escritura deja de ser una entelequia para convertirse en un instrumento que hay que aprender a dominar por motivos estéticos y prácticos a la vez, sobre todo porque en algunos medios la lengua escrita carece de valor y se precisa una fuerte motivación para que el niño sienta la necesidad de escribir. Para conseguirlo, se puede partir de situaciones reales: cartas, en los casos de correspondencia escolar, confección de car- 
teles para anunciar algún suceso relevante en el barrio o en la escuela, etc...y también a partir de experiencias personales y de aspectos de la vida cotidiana que susciten interés. La motivación está relacionada con los objetivos: hay motivación si los objetivos son útiles.

En este sentido la revista escolar resulta ser un buen canal para recoger las informaciones surgidas de los alumnos y a la vez, un receptor adecuado de los diversos tipos textuales. Se convierte así en un excelente argumento para trabajar la lengua escrita de manera significativa.

A lo largo del curso abundan las oportunidades de trabajar las funciones en la lengua escrita, tanto porque se establece una relación lógica entre la lengua escrita y las demás materias, como porque se aprovechan para trabajar los acontecimientos que van sucediendo: Como ejemplo:

\begin{tabular}{|c|c|c|c|c|c|c|}
\hline tipo de texto & Sant Jordi & Fiestas & Revista & Plástica & Soc./Nat. & Música \\
\hline descriptivo & - diversos & . & . & & $\begin{array}{l}\text { - diversos } \\
\text { - definicio- } \\
\text { nes de } \\
\text { términos } \\
\text { (dicciona- } \\
\text { rio de cla- } \\
\text { se) } \\
\text { - descrip- } \\
\text { ciones }\end{array}$ & . \\
\hline
\end{tabular}

\begin{tabular}{lll}
\hline narrativo $\bullet$ diversos & $\bullet$ diversos & \\
\hline explicativo & $\bullet$ diversos \\
& $\bullet$ definición \\
& de térmi- \\
& nos (dic- \\
& cionario \\
de clase) & $\bullet$ resúme- \\
& nes \\
\hline
\end{tabular}

\begin{tabular}{|c|c|c|c|c|c|}
\hline $\begin{array}{l}\text { argumenta- } \\
\text { ción }\end{array}$ & & & - diversos & & \\
\hline instructivo & $\begin{array}{l}\text { - bases del } \\
\text { concurso } \\
\text { - cartel }\end{array}$ & $\begin{array}{l}\text { - programa } \\
\text { cartel }\end{array}$ & $\begin{array}{l}\text { recetas de } \\
\text { cocina } \\
\text { reglas de } \\
\text { los juegos }\end{array}$ & & \\
\hline predictivo & & & $\begin{array}{l}\text { horósco- } \\
\text { pos }\end{array}$ & & \\
\hline $\begin{array}{l}\text { conversa. } \\
\text { cional }\end{array}$ & - diversos & & - diversos & & \\
\hline retórico & - diversos & - pregón & $\begin{array}{l}\text { - diversos } \\
\text { - portada }\end{array}$ & $\begin{array}{l}\text { - relación } \\
\text { p o e - } \\
\text { sía/dibu- } \\
\text { jo } \\
\text { caligra- } \\
\text { mas }\end{array}$ & $\begin{array}{l}\text { - musicar, } \\
\text { inventar } \\
\text { cancion- } \\
\text { cillas } \\
\text { - cambiar } \\
\text { letras de } \\
\text { canciones }\end{array}$ \\
\hline
\end{tabular}

Además, en las zonas donde conviven dos lenguas, hay propuestas que no es necesario repetir en las dos (catalán y castellano en el caso de Cataluña) porque son mecanismos aplicables a ambas por igual. De este modo, una vez han aprendido los alumnos a puntuar un diálogo en una lengua, no es preciso repetir el mismo trabajo en la otra. En cambio existen aspectos que es conveniente analizar en las dos por separado, como, por ejemplo, la descripción literaria o la 
poesía, porque intervienen elementos estilísticos propios de cada sistema lingüístico.

Para que el aprendizaje resulte eficaz es preciso que los equipos de educadores trabajen de forma homogénea y en una misma dirección. No tendría ninguna eficacia trabajar el texto narrativo en $3^{\circ}$ y no volverlo a manejar hasta $8^{\circ}$; asegurar un aprendizaje cualquiera significa retomar el tema de manera periódica, y ampliarlo de acuerdo con las posibilidades del alumno.

Por otro lado, la propuesta que aquí presentamos es bastante extensa y no permite que todos los temas aparezcan con la misma frecuencia en cada curso. Será preciso, pues, que la escuela organice las actividades de escritura en un proceso temporal intermitente que determine la práctica de los tipos textuales y su frecuencia en cada nivel. Tan sólo así podemos asegurar una continuidad imprescindible para la eficacia de los resultados.

Como posible modelo, proponemos el siguiente esquema de frecuencias de tratamiento a lo largo del curso, centrado en este caso en el Ciclo Medio, pero extensible a la totalidad de la EGB:

\begin{tabular}{lccc} 
tipo de texto & $3^{\circ}$ & $4^{\circ}$ & $5^{\circ}$ \\
\hline explicativo & 2 & 2 & 3 \\
descriptivo & 1 & 2 & 3 \\
instructivo & 1 & 2 & 3 \\
narrativo & 9 & 12 & 12 \\
retórico & 3 & 4 & 5 \\
conversacional & $?$ & $?$ & $?$ \\
argumentativo & $?$ & $?$ & $?$ \\
predictivo & $?$ & $?$ & $?$
\end{tabular}

Si bien es cierto que el alumno es capaz de distinguir e incluso de producir de manera intuitiva diversos tipos de texto, cada uno posee unas características formales y de contenido que lo definen a la par que exigen un trabajo escolar sistemático. La metodología que proponemos en la segunda parte de este artículos contempla siempre una primera fase de observación y análisis del texto, y una segunda fase de producción específica del alumno. La aplicación la hemos realizado sobre los modelos de texto de tipo descriptivo, explicativo, narrativo, instructivo y retórico. Hemos prescindido del tipo argumentativo porque resulta inadecuado para el Ciclo Medio; también del tipo predictivo a causa de su escaso rendimiento, y del conversacional porque, de algún modo, queda incluido dentro del tipo narrativo, a no ser que se proponga un trabajo teatral, por ejemplo, exponente claro de esta tipología. Es evidente que el maestro deberá establecer la lógica adecuación para cada nivel y para cada grupo-clase.

\section{Notas}

Dolz ratifica esta afirmación en un artículo sobre la expresión escrita dentro de la escuela: «Los resultados de una encuesta realizada a 87 enseñantes del ciclo superior de la escuela primaria suiza muestran que en el citado nivel escolar se trabaja de forma casi exclusiva sobre la narración y la descripción», La producció de texts escrits a l'escola, Joaquim Dolz. Universidad de Ginebra.

\section{Referencias}

ADAm, J. M., (1985), Quel types de textes?, Le français dans le monde, 192.

BLANCHE-BENVENISTE, C., (1982) «La escritura del lenguaje dominguero», dentro de Nuevas perspectivas sobre los procesos de lectura y escritura, México: Siglo XXI. 
BRONCKART, Y. P., (1985), Las ciencias del lenguaje: ¿Un desafio para la enseñanza?, UNESCO.

Cassany, D., (1987), Descriure escriure, Barcelona: Empúries.

CAZDEN, C. B., (1982) «La lengua escrita en contextos escolares», en Nuevas perspectivas sobre los procesos de lectura y escritura, México: Siglo XXI.

Jakobson, R., (1975) Ensayos de lingüistica general, Seix Barral 1975 (citado en Coromina, E. Practiques d'expresió $i$ comunicació, Vic, Eumo 1984

VYGOTSKI, L.S., (1972) «La creazione letteraria nell'età scolares», dentro de Immaginazione e creatività nell'età infantile, Roma, Editori Reuniti (Traducido al castellano en Infancia y Aprendizaje 27/28, 1984, pp. 115/116)

La lengua escrita en el Ciclo Medio. I. N. Vilà. CL\&E, 1989, 3-4, pp. 129-141.

\section{Resumen}

En este articulo se exponen las bases teóricas para la enseñanza-aprendizaje de la lengua escrita en la escuela.

Estas bases, elaboradas a partir de la clasificación textual de Adam, contemplan la naturaleza interdisciplinaria del lenguaje y, por lo tanto, las relaciones entre el lenguaje y las distintas materias escolares.

Sobre sobre la autora:

Nuria Vilà es profesora de Didáctica de la Lengua de la Escuela de Formación del Profesorado de EGB de la Universidad Autónoma de Barcelona. Su área de interés se centra en la lengua escrita.

\section{Dirección:}

Universidad Autónoma de Barcelona. Escuela de Formación del Profesorado de E.G.B. San Cugat del Vallès. 08071 Barcelona.

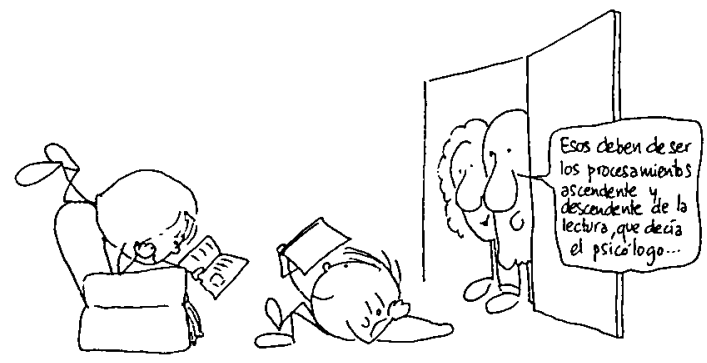

